\title{
Inverted Nipple Correction Using a Combination of the Perpendicular Suture Method and the Purse-String Suture Method
}

Jae Kyoung Kang ${ }^{1}$, Byung Min Yun², Jung-Kook Song ${ }^{3}$, Myoung Soo Shin ${ }^{2}$

${ }^{1}$ Department of Plastic and Reconstructive Surgery, Jeju National University Hospital, Jeju; ${ }^{2}$ Department of Plastic and Reconstructive Surgery, Jeju National University School of Medicine, Jeju;

${ }^{3}$ Department of Preventive Medicine, Jeju National University School of Medicine, Jeju, Korea

This work was supported by a 2017 education, research and student guidance grant funded by Jeju National University.

No potential conflict of interest relevant to this article was reported.
While various surgical methods are used for inverted nipple correction, an optimal technique has not been established. We describe a combination of suture methods including purse-string sutures, based on a report by Gould et al. This is a simple and safe method for inverted nipple correction.

Keywords Nipples, Suture techniques

\section{INTRODUCTION}

Inverted nipple is defined as a state in which part of the nipple or the entire nipple is retracted below the surface of the areola. Inverted nipples can be classified in accordance with Han and Hong's classification [1] as follows: grade I (mild), grade II (moderate), and grade III (severe).

Surgical correction aims to achieve aesthetically satisfactory nipple projection without recurrence, while also maintaining the sensory and lactation functions [2]. Various surgical methods have been suggested for correcting inverted nipples, including dermal and dermoglandular flaps, endoscopic release, internal suturing, continuous traction, and the use of artificial dermis [3-8]. The va-

Received: Apr 11, 2017 Revised: May 15, 2017 Accepted: May 15, 2017 Correspondence: Myung Soo Shin Department of Plastic and Reconstructive Surgery, Jeju National University Hospital, 15 Aran 13-gil, Jeju 63241, Korea. E-mail: ms57@unitel.co.kr

Copyright @ 2017 The Korean Society for Aesthetic Plastic Surgery.

This is an Open Access article distributed under the terms of the Creative Commons Attribution Non-Commercial License (http://creativecommons.org/licenses/by-nc/4.0/) which permits unrestricted non-commercial use, distribution, and reproduction in any medium, provided the original work is properly cited. www.e-aaps.org riety of surgical techniques reflects the difficulty of achieving a satisfactory outcome with any single method.

A surgical technique employing 2 horizontal mattress sutures was suggested by Gould et al. [9] in 2015. This is a relatively safe and effective method, but we found that the shape of the nipple base immediately after surgery was angular, and that satisfactory nipple projection was difficult to achieve with time; accordingly, we developed a new method, as described in this report. Using the surgical method of Gould et al. [9] as a benchmark, we surmised that combining this technique with purse-string suturing would produce a better outcome. Thus, we introduce a surgical technique that combines 2 suture-based methods.

\section{IDEA}

Surgical procedure

Gould et al. [9] proposed a surgical method for correcting inverted nipples in 2015. Four slit incisions are made in the nipple base (at the $3,6,9$, and 12 oclock positions) while the patient is under local anesthesia, and the fibrotic band located at the nipple base is dissected and released. Next, 2 horizontal mattress sutures are performed in a perpendicular direction with 4-0 Vicryl (Fig. 1). We 

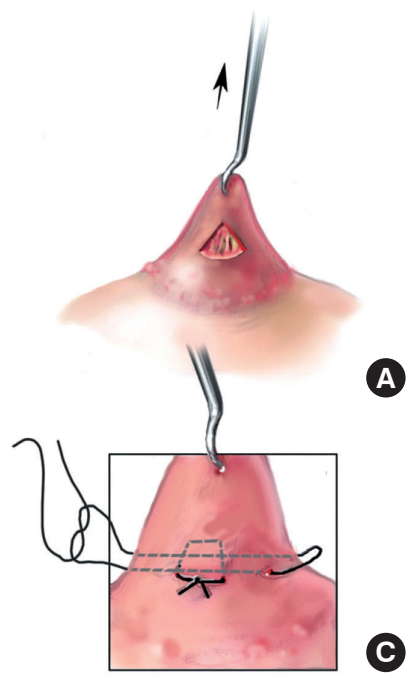

A

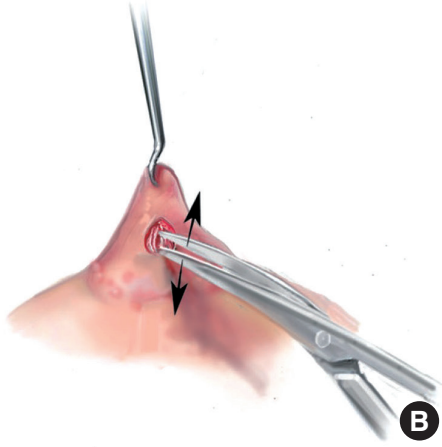

C

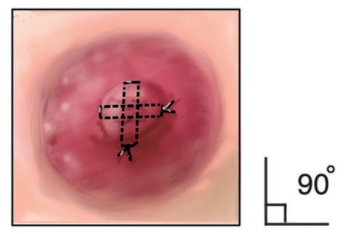

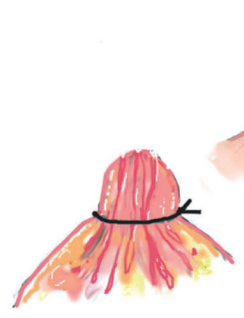

$\boldsymbol{E}$

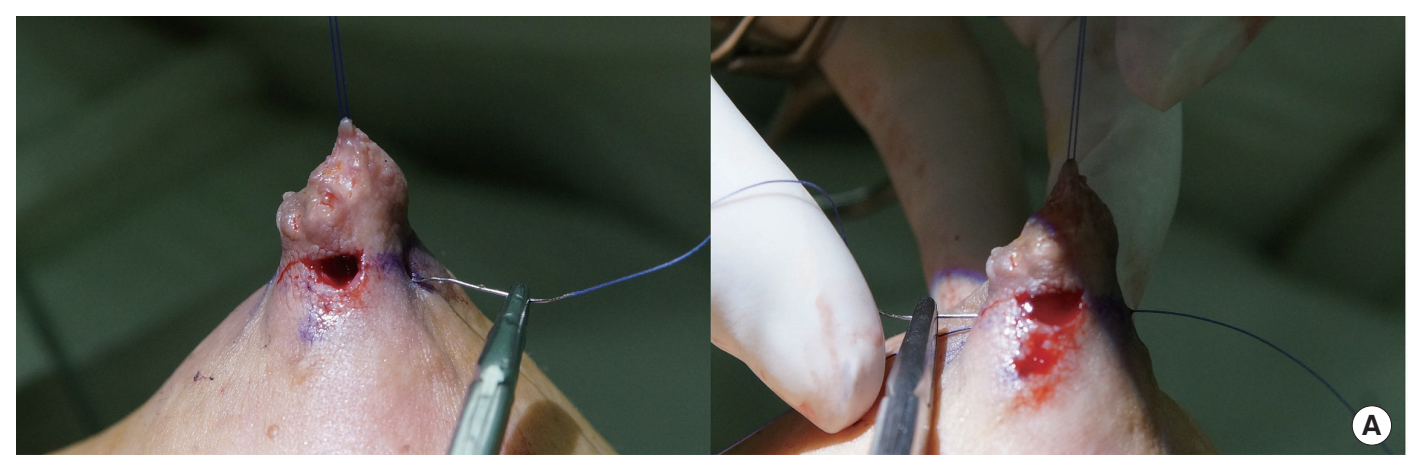

Fig. 1. Schematic drawing of the operative procedure of Gould et al. [Reprinted from “ Inverted nipple repair revisited: a 7-year experience", by Gould DJ, Nadeau MH, Macias LH, and Stevens WH, 2015, Aesthet Surg J, 35, pp.156-64. Copyright 2015 by the Oxford University Press. Reprinted with permission].
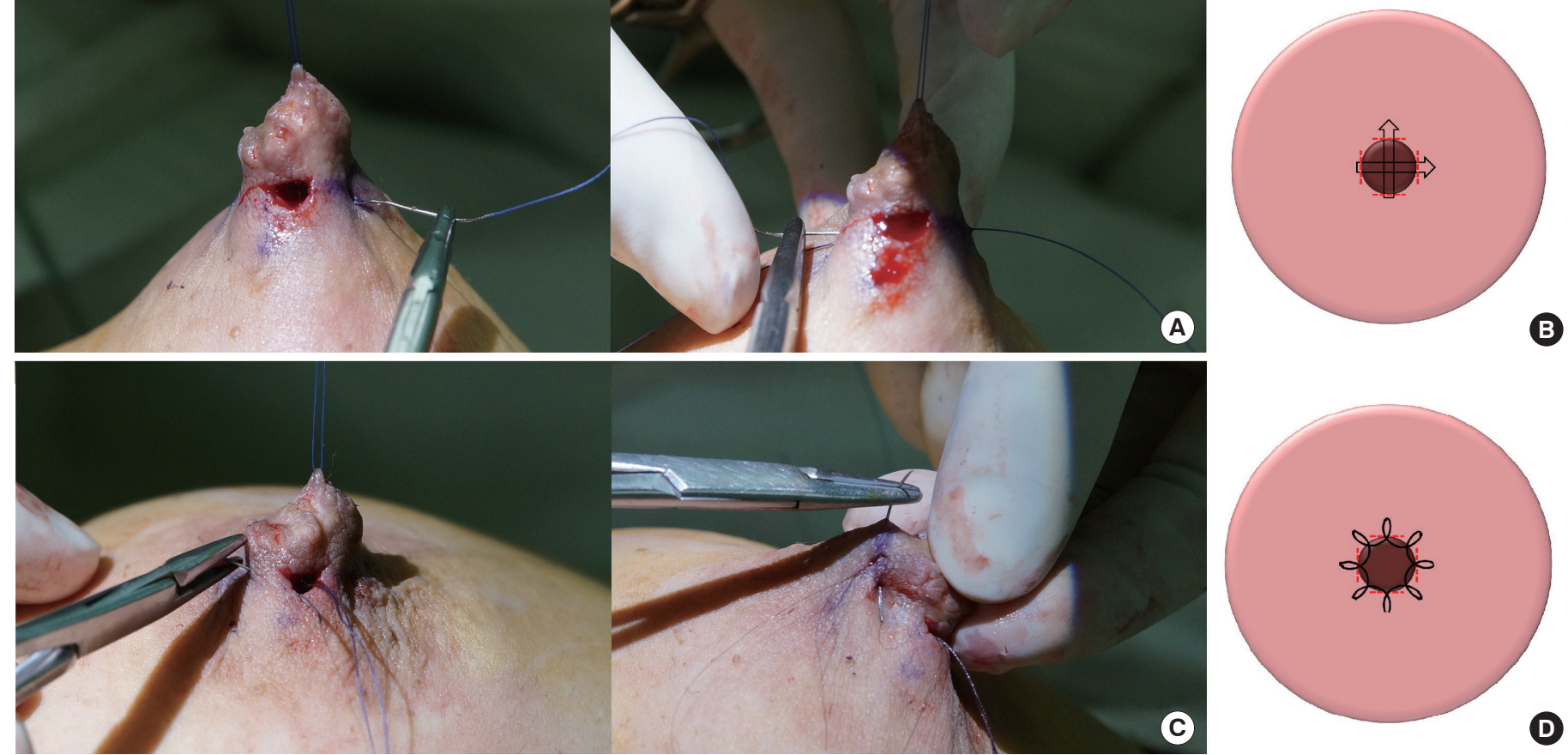

Fig. 2. (A) Four incisions were made at the 12, 3, 6, and 9 o'clock points. The first horizontal mattress suture extended from the 6 o'clock point to the 12 o'clock point. (B) Schematic drawing of the 2 horizontal mattress sutures in a perpendicular direction. (C) The start of purse-string suture placement through an incision at the 6 o'clock position, and reinsertion of the suture through the stitch exit points. (D) Schematic drawing of the purse-string suture.

used the same method described above, but followed this with a purse-string suture without an additional incision, as in non-incisional double eyelidplasty or knifeless otoplasty. Starting from the slit incision at the 6 oclock position, a purse-string suture was placed around the nipple base with 7-0 nylon, followed by 8 stitch points at equal intervals.

The length of the skin incision for the horizontal mattress su- tures must be limited to 3 to $5 \mathrm{~mm}$, and no separate incision was made for the purse-string suture. When performing the purse-string suture, a needle was inserted back into the stitch points from which it came out, without a skin incision. The purse-string suture was ligated with proper tension, and the knot was buried beneath the dermis (Fig. 2). The skin incisions were then sutured with 7-0 nylon, antibiotic ointment was applied, gauze was loosely placed, and 

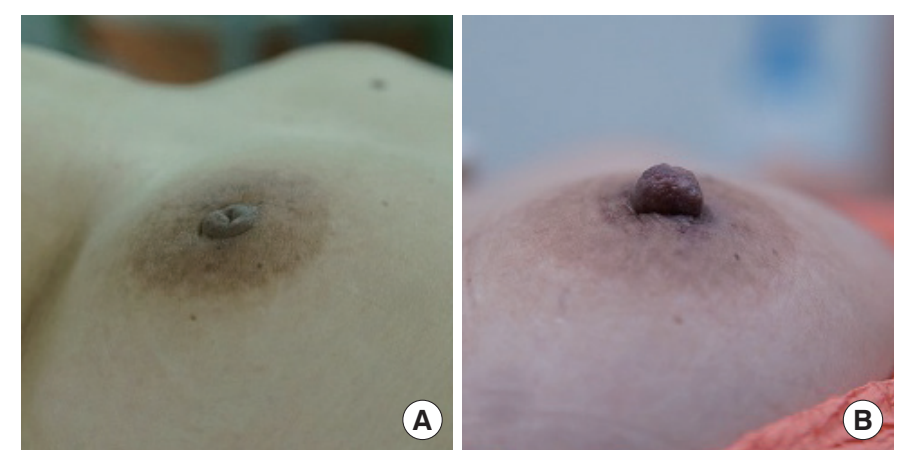

Fig. 3. (A) Before the operation and (B) 6 months afterward.

the wound was disinfected with a nipple protection cup. The temporary traction suture was not removed, but was tied to the nipple protection cup to maintain traction. This traction was removed after 3 to 5 days.

\section{Case}

A 50-year-old woman underwent surgery for grade II inverted nipple in her right breast. The patient was monitored for 6 months postoperatively, during which time there were no adverse effects, such as hematoma, bleeding, nipple necrosis, or sensory loss (Fig. 3). The nipple was well maintained without any significant loss of projection after surgery, and the patient was satisfied with the surgical outcome.

\section{DISCUSSION}

The creation of lasting nipple projection remains a challenging problem in the correction of inverted nipples. Surgical techniques to correct inverted nipples have been studied, and various methods have been suggested, such as dermal and dermoglandular flaps, endoscopic release, internal suturing, continuous traction, and the use of artificial dermis [3-8,10]. Techniques using sutures have the advantage of reducing incisions and scarring, and are also considered safe. Perpendicular sutures, purse-string sutures, and continuous subcutaneous sutures have been used [11-14]. In particular, we thought that the surgical method published in 2015 by Gould et al. [9] was a safe and effective technique to correct inverted nipples. Therefore, we performed this technique on our patients, but in some cases the patients were not satisfied with the result. They complained of an angular nipple base immediately after surgery and gradual nipple projection loss. However, these patients did not agree for their clinical photographs to be used, meaning that unfortunately there are no clinical photographs in this article.

The technique described herein combines perpendicular absorbable sutures and purse-string non-absorbable sutures. Our surgical method involves first placing a pair of perpendicular sutures using a horizontal mattress suture technique with 4-0 absorbable materi- al, followed by a purse-string suture with 7-0 non-absorbable material. The horizontal mattress sutures provide basic support for the maintenance of nipple projection immediately after surgery, and the purse-string suture provides additional strength to maintain projection. Use of a purse-string suture with non-absorbable material prevents the loss of projection with the gradual absorption of the horizontal mattress suture, in which an absorbable material is used. Moreover, the purse-string suture helps to form a nipple base with a more circular shape after surgery.

In the surgical technique presented in our study, 7-0 nylon is used for the purse-string suture, which is finer than the sutures used in previous methods, and only 8 stitches are needed $[12,13]$. The reduced number of stitches makes surgery simpler than other pursestring suture techniques, thereby reducing the duration of surgery. In addition, the finer thread should reduce the likelihood of the suture material being palpable or exposed after recovery. The strength needed to maintain the projection is reduced by the use of fewer stitches and finer thread, but is compensated for by the use of perpendicular sutures. Combining 2 suture techniques to maintain projection prevents excessive force on the purse-string suture, thereby reducing the risk of reduced blood supply to the nipple [13].

Inverted nipples still present a challenge for plastic surgeons. Our combined use of 2 different suture techniques to provide sustained nipple projection is simple, safe, and reliable. However, the followup duration in this study was relatively short, and additional longterm monitoring will be required.

\section{PATIENT CONSENT}

Patients provided written consent for the use of their images.

\section{REFERENCES}

1. Han S, Hong YG. The inverted nipple: its grading and surgical correction. Plast Reconstr Surg 1999;104:389-95.

2. Shiau JP, Chin CC, Lin MH, et al. Correction of severely inverted nipple with telescope method. Aesthetic Plast Surg 2011;35:1137-42.

3. Lee HB, Roh TS, Chung YK, et al. Correction of inverted nipple using strut reinforcement with deepithelialized triangular flaps. Plast Reconstr Surg 1998;102:1253-8.

4. Burm JS, Kim YW. Correction of inverted nipples by strong suspension with areola-based dermal flaps. Plast Reconstr Surg 2007;120:1483-6.

5. Chen SH, Gedebou T, Chen PH. The endoscope as an adjunct to correction of nipple inversion deformity. Plast Reconstr Surg 2007;119: 1178-82.

6. Serra-Renom J, Fontdevila J, Monner J. Correction of the inverted nipple with an internal 5-point star suture. Ann Plast Surg 2004;53:293-6.

7. Teng L, Wu GP, Sun XM, et al. Correction of inverted nipple: an alternative method using continuous elastic outside distraction. Ann Plast Surg 2005;54:120-3. 
8. Yamada N, Kakibuchi M, Kitayoshi H, et al. A method for correcting an inverted nipple with an artificial dermis. Aesthetic Plast Surg 2004; 28:233-8.

9. Gould DJ, Nadeau MH, Macias LH, et al. Inverted nipple repair revisited: a 7-year experience. Aesthet Surg J 2015;35:156-64.

10. McGeorge DD. The "Niplette": an instrument for the non-surgical correction of inverted nipples. Br J Plast Surg 1994;47:46-9.

11. Sapountzis S, Kim JH, Minh P, et al. Correction of inverted nipple with "arabesque"-shape sutures. Aesthetic Plast Surg 2012;36:339-42.
12. Peled IJ. Purse-string suture for nipple projection. Plast Reconstr Surg 1999;103:1480-2.

13. Kolker AR, Torina PJ. Minimally invasive correction of inverted nipples: a safe and simple technique for reliable, sustainable projection. Ann Plast Surg 2009;62:549-53.

14. Cabalag MS, Chui CH, Tan BK. Correction of nipple inversion using a micro-knife and transverse to longitudinal skin closure. J Plast Reconstr Aesthet Surg 2010;63:e627-30. 